\title{
65
}

\section{A Neural Network Algorithm for Solving the Job-Shop Scheduling Problem with Priority}

Jianfei Chen and Shaowei Xia

Dept. of Automation, Tsinghua University, Beijing 100084, China

National Laboratory of Pattern Recognition, Beijing 100080, China

\begin{abstract}
Hopfield-type neural networks have shown part success in solving hard optimization problem. As problem becomes more and more complex, it is increasingly difficult to find a suitable encoding of constraints into an energy function, which will effectively guide the network to a desired solution. This paper describes how the job-shop scheduling problem with priority is encoded into a modified Hopfield neural network, and solved. The neural network algorithm is easy to be virtually realised on digital computers. At the end an example is given.
\end{abstract}

\section{Keywords}

NP-hard, neural network, job-shop scheduling problem, priority

\section{INTRODUCTION}

The job-shop scheduling problem (JSSP) is a resources to tasks allocation problem. The resources are usually called machines, the tasks jobs. Each job may consist of several subjobs (refered to as operations) which subject to some precedence restrictions. The job-shop scheduling is a classical operations research problem with numerous applications but very few practical solution approaches. Due to the large number of constraints the problem is known to be NP-hard one, so that even a good (which may be not optimal) feasible solution is acceptable in most applications. The scheduling problem with priority is one important class among the scheduling problems, and this paper especially introduces the neural network algorithm for solving it. 


\section{FORMAL DESCRIPTION OF GENERAL JSSP}

Let $S_{i k}$ denote the starting time and $t_{i k}$ the processing time for operation $k$ of job $i$. The cost function will be the sum of the starting time of each job's last operation: $\sum_{i=1}^{n} S_{i k_{i}}$, where $n$ is the number of jobs, $k_{i}$ is the last operation of job i. The total waiting and processing time for all jobs equals $\sum_{i=1}^{n} S_{i \mathbf{k}_{\mathbf{i}}}+\sum_{\mathrm{i}=1}^{\mathrm{n}} \mathrm{t}_{\mathbf{i} \mathbf{k}_{\mathbf{i}}}$ where $\sum_{i=1}^{n} t_{i k_{1}}$ is a constant.

The precedence constraints are given by the following inequality:

$\mathrm{S}_{\mathrm{ik}}-\mathrm{S}_{\mathrm{i}, \mathrm{k}+1}+\mathrm{t}_{\mathrm{ik}} \leqslant 0, \quad \mathrm{i}=1, \cdots, \mathrm{n} ; \mathrm{k}=1, \cdots, \mathrm{k}_{\mathrm{i}}-1$

The starting time should be positive, so

$\mathrm{S}_{\mathrm{il}} \geqslant 0, \quad \mathrm{i}=1, \cdots, \mathrm{n}$.

For any two operations $(i, k)$ and $(j, p)$ assigned to the same machine (where the first index denotes the job number and the second index the operation number), the following constraints need to be satisfied in order to avoid the overlap in time between these operations: $S_{i k}-S_{j p}+t_{i k} \leqslant 0$, if operation ( $i$, $k$ ) is performed first; or $S_{j p}-S_{i k}+t_{j p} \leqslant 0$, if operation $(j, p)$ is performed first.

In conclusion the mathematical formulation for the job-shop scheduling is described as follows (Zhou and etc. , 1990):

$$
\begin{aligned}
\min & \sum_{\mathrm{i}=1}^{\mathrm{n}} \mathrm{S}_{\mathrm{ik}_{\mathrm{i}}} \\
\mathrm{s} . \mathrm{t} . & \mathrm{S}_{\mathrm{ik}}-\mathrm{S}_{\mathrm{i}, \mathrm{k}+1}+\mathrm{t}_{\mathrm{ik}} \leqslant 0, \quad \mathrm{i}=1, \cdots, \mathrm{n} ; \mathrm{k}=1, \cdots, \mathrm{k}_{\mathrm{i}}-1 \\
& \mathrm{~S}_{\mathrm{il}} \geqslant 0, \quad \mathrm{i}=1, \cdots, \mathrm{n} \\
& \mathrm{S}_{\mathrm{ik}}-\mathrm{S}_{\mathrm{jp}}+\mathrm{t}_{\mathrm{ik}} \leqslant 0 \text { or } \quad \mathrm{S}_{\mathrm{jp}}-\mathrm{S}_{\mathrm{ik}}+\mathrm{t}_{\mathrm{jp}} \leqslant 0
\end{aligned}
$$

In addition, there is another constraint,

$\mathrm{S}_{\mathrm{ik}_{\mathrm{i}}} \leqslant \operatorname{expect}_{\mathrm{i}}, \quad \mathrm{i}=1, \cdots, \mathrm{n}$

If job $i$ has due date expect $t_{i}$ equals the due date, otherwise expect t $_{i}$ may take an enough large number. 


\section{PROPOSED NEURAL NETWORK FOR GENERAL JSSP}

\section{1 Energy function}

The energy function of the neural network is chosen as follows :

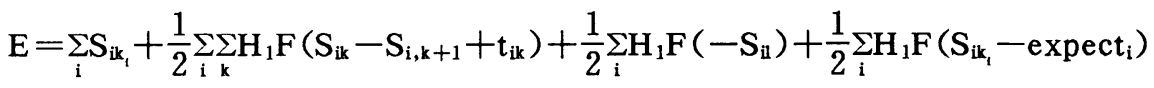

$$
\begin{aligned}
& +\frac{1}{2} \sum_{\mathrm{ik} j \mathrm{j}} \mathrm{H}_{2} \mathrm{~F}\left(\min \left(\mathrm{S}_{\mathrm{ik}}-\mathrm{S}_{\mathrm{jp}}+\mathrm{t}_{\mathrm{ik}}, \mathrm{S}_{\mathrm{jp}}-\mathrm{S}_{\mathrm{ik}}+\mathrm{t}_{\mathrm{jp}}\right)\right)
\end{aligned}
$$

where $H_{1}, H_{2}$ are all big positive parameters, $H_{1} \gg H_{2} . F(x)= \begin{cases}x^{2}, & x>0 \\ 0, & x \leqslant 0\end{cases}$

\section{2 Motion equations}

The motion equations of the neural network are stated as follows :

$\frac{\mathrm{d} S_{\mathrm{ik}}}{\mathrm{dt}}=-\frac{\partial \mathrm{E}}{\partial \mathrm{S}_{\mathrm{ik}}}$

$\triangle S_{i k}(t)= \begin{cases}\min \left(2^{q}, L_{i k}(t)-S_{i k}(t)\right), & \text { if } \frac{d S_{i k}}{d t} \geqslant 2^{q-1} w_{i k, i k} \\ \max \left(-2^{q},-S_{i k}(t)\right), & \text { else if } \frac{d S_{i k}, \text { ik }}{d t}<-2^{q-1} w_{i k, i k} \\ 0, & \text { else }\end{cases}$

$\mathrm{S}_{\mathrm{ik}}(\mathrm{t}+1)=\mathrm{S}_{\mathrm{ik}}(\mathrm{t})+\triangle \mathrm{S}_{\mathrm{ik}}(\mathrm{t})$

$$
\mathrm{i}=1, \cdots, \mathrm{n} ; \mathrm{k}=1, \cdots, \mathrm{k}_{\mathrm{i}} ; \mathrm{q}=0, \cdots, \mathrm{b}_{\mathrm{m}}-1
$$

The processing times are all integer numbers; even not, they may be converted into integer numbers. $S_{i k}$ can also be thought of as integer numbers, and $b_{m}$ is the maximum bits of binary digit needed to represent $S_{\mathbf{i k}_{\mathbf{k}}} \cdot \mathrm{LS}_{\mathbf{i k}_{\mathbf{k}}}=$ expect $_{\mathbf{i}}$ $-t_{i \mathbf{k}_{1}}, L S_{i k}=L S_{i, k+1}-t_{i, k+1}, i=1, \cdots, n ; k=k_{i}-1, \cdots, 1$.

The initial values of $S_{i k}$ are selected as follows :

$\mathrm{S}_{\mathrm{il}}=0, \mathrm{~S}_{\mathrm{ik}}=\mathrm{S}_{\mathrm{i}, \mathrm{k}-1}+\mathrm{t}_{\mathrm{i}, \mathrm{k}-1}, \mathrm{i}=1, \cdots, \mathrm{n} ; \mathrm{k}=2, \cdots, \mathrm{k}_{\mathrm{i}}$

Determination of $w_{i k, i k}$ : Assumpting the coefficient matrix of (1) is $A$, the coefficient matrix of (3) $\mathrm{A}_{1}$, 
$\mathrm{W}=\mathrm{H}_{1} \mathrm{~A}^{\mathrm{T}} \mathrm{A}+\frac{1}{2} \mathrm{H}_{2} \mathrm{~A}_{1}^{\mathrm{T}} \mathrm{A}_{1}$

and $\mathbf{w}_{\mathrm{ik}, \mathrm{ik}}$ is the $i k$ th diagonal element (corresponding to $\mathrm{S}_{\mathrm{ik}}$ ) of $\mathrm{W}$.

It may be proved that the function $E$ in (5) will monotonously decrease if $\mathrm{S}_{\mathrm{ik}}$ change according to the motion equations (6), (7) and (8).

\section{3 'Hill-climbing' term}

Rather than use a stochastic technique to enable the neural network to escape from local energy minima (which may correspond to infeasible solutions), a simple but effective 'hill-climbing' term was added to the motion equations, that is,

$$
\begin{aligned}
\frac{d S_{i k}}{d t}= & -\frac{\partial E}{\partial S_{i k}}-\sum_{j p} H_{3} h\left(\min \left(S_{i k}-S_{j p}+t_{i k}, S_{j p}-S_{i k}+t_{j p}\right)\right) \\
& \times \operatorname{select}\left(S_{i k}-S_{j p}+t_{i k}, S_{j p}-S_{i k}+t_{j p}\right)
\end{aligned}
$$

where $\mathrm{H}_{3}$ is a positive parameter, $\mathrm{H}_{3}>\mathrm{H}_{1}$.

$h(x)=\left\{\begin{array}{ll}1, & x>0 \\ 0, & x \leqslant 0\end{array}, \quad \operatorname{select}(x, y)= \begin{cases}1, & x \leqslant y \\ -1, & x>y\end{cases}\right.$

\section{4 Implemented method}

The value of $\mathrm{H}_{3}$ is selected by trial and error, and is hard to get a suitable amount. If $\mathrm{H}_{3}$ is too small the 'hill-climbing' term can not make effectiveness, if $\mathrm{H}_{3}$ is too big the neural network will oscillate. Therefore in the implemented method we avoid the selection of the value of $\mathrm{H}_{3}$, taking adjustment instead of 'hill-climbing' term. The rules for adjustment are:

if $\mathrm{S}_{\mathrm{jp}}<\mathrm{S}_{\mathrm{ik}}<\mathrm{S}_{\mathrm{jp}}+\mathrm{t}_{\mathrm{jp}}$

if $L S_{i k} \geqslant S_{j p}+t_{j p}$ then $S_{i k}=S_{j p}+t_{j p}$

else if $L S_{j p} \geqslant S_{i k}+t_{i k}$ then $S_{j p}=S_{i k}+t_{i k}$

if $\mathrm{S}_{\mathrm{ik}}<\mathrm{S}_{\mathrm{jp}}<\mathrm{S}_{\mathrm{ik}}+\mathrm{t}_{\mathrm{ik}}$

if $L S_{\mathrm{jp}} \geqslant S_{\mathrm{ik}}+\mathrm{t}_{\mathrm{ik}}$ then $\mathrm{S}_{\mathrm{jp}}=\mathrm{S}_{\mathrm{ik}}+\mathrm{t}_{\mathrm{ik}}$

else if $L S_{i k} \geqslant S_{j p}+t_{j p}$ then $S_{i k}=S_{j p}+t_{j p}$

if $S_{i k}=S_{j p}$ and $t_{i k} \leqslant t_{j p}$

if $L_{\mathrm{jp}} \geqslant \mathrm{S}_{\mathrm{ik}}+\mathrm{t}_{\mathrm{ik}}$ then $\mathrm{S}_{\mathrm{jp}}=\mathrm{S}_{\mathrm{ik}}+\mathrm{t}_{\mathrm{ik}}$

else if $L S_{i k} \geqslant S_{j p}+t_{j p}$ then $S_{i k}=S_{j p}+t_{j p}$ 
if $\quad \mathrm{S}_{\mathrm{ik}}=\mathrm{S}_{\mathrm{jp}}$ and $\mathrm{t}_{\mathrm{jp}}<\mathrm{t}_{\mathrm{ik}}$

if $L S_{i k} \geqslant S_{j p}+t_{j p}$ then $S_{i k}=S_{j p}+t_{j p}$

else if $L S_{j p} \geqslant S_{i k}+t_{i k}$ then $S_{j p}=S_{i k}+t_{i k}$

In conclusion $S_{i k}\left(i=1, \cdots, n ; k=1, \cdots, k_{i}\right)$ evolve in light of the motion equations (6)、(7) and (8), and are sequently adjusted by the above-mentioned rules. The evolution and adjustment are repeated until $S_{\mathrm{ik}}$ freeze not only in evolution but also in adjustment.

It may be proved that the implemented method will certainly converge and the solution obtained by it must be feasible.

\section{ALGORITHM FOR THE JSSP WITH PRIORITY}

In the JSSP with priority, the jobs have different priorities. The jobs may be scheduled in order according to their priorities (from the highest to the lowest). Moreover, when scheduling the jobs with low priority, the time table of the jobs with higher priorities is not admitted to be delayed. For the consideration, the algorithm for the JSSP with priority may consists of the following steps :

1. Assumpting $L S_{i k}$ is the latest start time of operation $(i, k)$, let $L S_{i k}=\infty$.

2. Schedule the job (s) i with the highest priority, and then let $\mathrm{LS}_{\mathrm{ik}}=\mathrm{S}_{\mathrm{ik}}, \mathrm{k}=$ $1, \cdots, \mathrm{k}_{\mathrm{i}}$.

3. Acording to priority, schedule the job(s) i with lower priority, and then let $\mathrm{LS}_{\mathrm{ik}}=\mathrm{S}_{\mathrm{ik}}, \mathrm{k}=1, \cdots, \mathrm{k}_{\mathrm{i}}$.

4. If there is (are) job (s) unscheduled, return to step 3 .

5. End.

\section{NEUMERIAL RESULTS}

A program to simulate the neural network algorithm was writen in $\mathrm{C}$ language on VAX 785. We tested many problems, and found that the neural network algorithm had been quite successful in finding valid schedules, and the solutions had been superior to those found by heuristic algorithms.

Table 1 gives a JSSP with priority. Figure 1,2,3 are the results found by the neural network algorithm, and the results have been known to be very good through comparision. 
Table 1 A JSSP with priority

\begin{tabular}{|c|c|c|}
\hline Jobs & $\frac{\text { Machine }}{\text { Process time }}$ & Priority \\
\hline 1 & $\begin{array}{ccc}\mathrm{M}_{1} & \mathrm{M}_{2} & \mathrm{M}_{3} \\
5 & 8 & 2\end{array}$ & 3 \\
\hline 2 & $\begin{array}{ccc}\mathbf{M}_{3} & \mathbf{M}_{1} & \mathbf{M}_{2} \\
7 & 3 & 9\end{array}$ & 3 \\
\hline 3 & $\begin{array}{ccc}\mathbf{M}_{1} & \mathbf{M}_{2} & \mathbf{M}_{3} \\
6 & 3 & 2\end{array}$ & 2 \\
\hline 4 & $\begin{array}{ccc}\mathrm{M}_{2} & \mathrm{M}_{3} & \mathrm{M}_{1} \\
4 & 3 & 4\end{array}$ & 2 \\
\hline 5 & $\begin{array}{cc}\mathrm{M}_{3} & \mathrm{M}_{2} \\
6 & 4\end{array}$ & 2 \\
\hline 6 & $\begin{array}{cc}\mathbf{M}_{1} & \mathbf{M}_{2} \\
2 & 3\end{array}$ & 1 \\
\hline 7 & $\begin{array}{ccc}\mathbf{M}_{3} & \mathbf{M}_{1} & \mathbf{M}_{3} \\
5 & 6 & 2\end{array}$ & 1 \\
\hline
\end{tabular}

\begin{tabular}{|c|c|c|}
\hline $\mathrm{M}_{1} \quad 1,1$ & 2,2 & \\
\hline $\mathrm{M}_{2}$ & 1,2 & 2,3 \\
\hline$M_{3} 2$, & & \\
\hline
\end{tabular}

Figure 1 Schedule of jobs with priority of 3.

\begin{tabular}{|c|c|c|c|c|c|}
\hline $\mathrm{M}_{1} \quad 1,1$ & 2,2 & 4,3 & 3,1 & & \\
\hline $\mathrm{M}_{2} \quad 4,1$ & 1,2 & & 2,3 & 3,2 & 5,2 \\
\hline $\mathrm{M}_{3} \square$ & 4,2 & & 5,1 & & 3,3 \\
\hline
\end{tabular}

Figure 2 Schedule of jobs with priorities of 3 and 2 . 


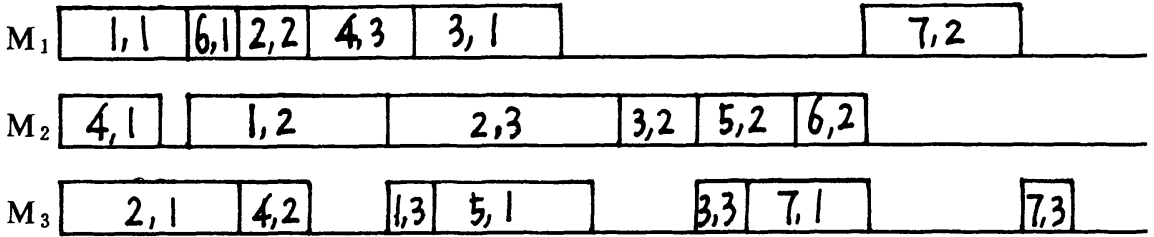

Figure 3 Schedule of all jobs.

\section{CONCLUSION}

The job-shop scheduling with priority is a kind of NP-hard problem. Although it has many application situations, there is few efficient method to solve it. After many tests we think that the neural network algorithm is a good candidate and merits further studies.

\section{REFERENCE}

Zhou, D. N. , Cherkassky, V. , Baldwin, T.R. and Hong, D. W. , (1990)" Scaling Neural Network for Job-Shop Scheduling ", Proc. IJCNN' 90, Vol. 3, 889-92, Washington, D. C.

\section{BIOGRAPHY}

Jianfei Chen is a $\mathrm{Ph}$. D. student in system engineering, department of automation, Tsinghua University. He has published several papers on discrete optimization, scheduling, multi-objective decision system, object-oriented analysis, and etc. . He is also temporarily a research fellow of National Laboratory of Pattern Recognition, Chinese Academy of Sciences.

Shaowei Xia is a professor in the department of automation, Tsinghua University. She graduated from the department of electrical engineering, Tsinghua University in 1953. Since then, she has worked in this university in the area of automation and system engineering. In 1980-1981, she visited the Nomura Institute in Japan as a visiting scholar. Her current research interest includes dynamic input-output models and regional linkage models, economyenergy-environmental system analysis; neural networkks and its applications. Shaowei Xia is a council member of system engineering federation of Chian, and a vice chairman of the social-economic system engineering society of China. 